\title{
MALT Lymphoma Diagnosed on Transbronchial Lung Biopsy: A Case Report
}

\section{Sandeep Gupta ${ }^{1 *}$, Kanu Goel² and Jasleen Kaur ${ }^{2}$}

${ }^{1}$ Department of Pulmonary Medicine and Critical Care, Amar Hospital, Patiala, India

${ }^{2}$ Department of Pathology, Columbia Asia Hospital, Patiala, India

\begin{abstract}
Mucosa associated lymphoid tissue lymphoma (MALToma) of the lung is a rare, low-grade B-cell lymphoma arising from the bronchus associated lymphoid tissue (BALT), usually requiring surgical biopsy using thoracoscopy for diagnosis. We present a case of MALToma of the lung diagnosed with a transbronchial lung biopsy (TBLB) specimen. A 63 year old man presented with hemoptysis. Chest $X$ ray disclosed right upper lobe consolidation. Pathological examination of the TBLB specimen revealed lymphocytic infiltrations that stained positive with CD 20 and CD 79a on immunohistochemical studies. Thus, TBLB is a valuable and relatively non invasive method for diagnosing primary pulmonary MALT Iymphoma.
\end{abstract}

Keywords: Non- Hodgkin's Lymphoma; MALToma; Transbronchial lung biopsy

Abbreviations: MALT: Mucosa Associated Lymphoid Tissue; MALToma: Mucosa Associated Lymphoid Tissue Lymphoma; BALT: Bronchus Associated Lymphoid Tissue; TBLB: Transbronchial Lung Biopsy; NHL: Non-Hodgkin’s Lymphoma

\section{Introduction}

Mucosa associated lymphoid tissue lymphoma (MALToma) is a low grade B-cell lymphoma which was described by Isaacson and Wright [1] in 1983. In the latest WHO classification, it belongs to the extranodal marginal zone lymphoma. The most common extranodal site of presentation for non-Hodgkin's lymphoma (NHL) is the gastrointestinal tract. Primary NHL of the lung is very rare, accounting for only $0.4 \%$ of all malignant lymphomas. Its development requires MALT of the bronchus that is thought to be acquired as a result of chronic antigenic stimulation such as smoking, autoimmune disease or infection [2]. It is often difficult to diagnose bronchial MALToma on TBLB specimens even after thorough histopathological and immunohistochemical examination, and surgical specimens by thoracotomy may be required to establish a firm diagnosis. We report a case of MALToma lung diagnosed using TBLB.

\section{Case Report}

A 63 year old male presented to our outpatient department

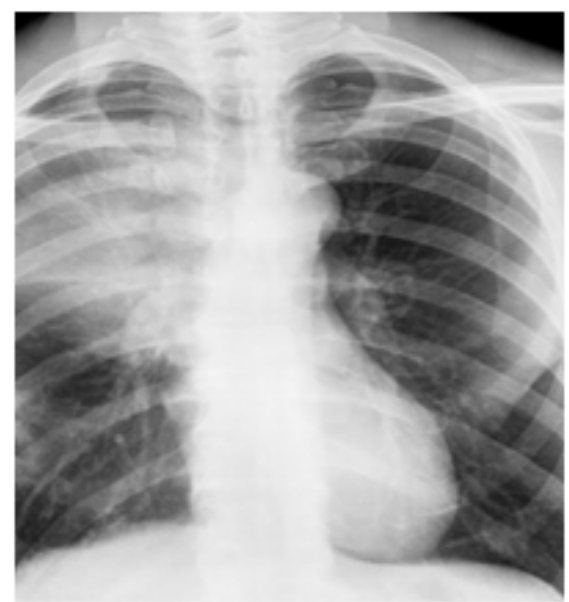

Figure 1a: Chest X-ray showing an abnormal shadow in the right upper lobe.

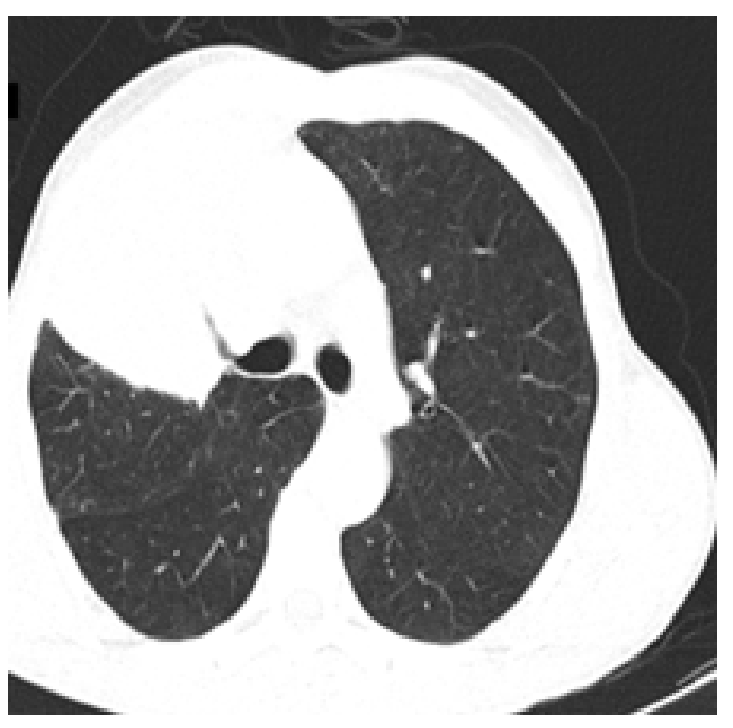

Figure 1b: Computed tomography chest showing segmental consolidation with areas of breakdown in the right upper and mid lobe.

describing hemoptysis of four months. He had no other significant chest complaints. There were no added sounds on auscultation, but breath sounds were reduced on the right side. There was no lymphadenopathy and organomegaly. The laboratory work up, including complete blood picture with differential counts, liver and renal function tests, was within normal limits. Both the bacterial culture and the acid fast bacilli smear examination of sputum were negative. An abnormal shadow in the right upper lobe was seen on chest X- ray (Figure 1a). Computed tomography of the chest showed segmental consolidation with areas of breakdown

${ }^{*}$ Corresponding author: Dr. Sandeep Gupta, Department of Pulmonary Medicine and Critical Care, Amar Hospital, Patiala, India, Tel: 91-9888391241; E-mail: dr_sandygupta@yahoo.com

Received January 17, 2012; Accepted March 12, 2012; Published March 14 2012

Citation: Gupta S, Goel K, Kaur J (2012) MALT Lymphoma Diagnosed on Transbronchial Lung Biopsy: A Case Report. J Pulmonar Respirat Med 2:117. doi:10.4172/2161-105X.1000117

Copyright: (C) 2012 Gupta S, et al. This is an open-access article distributed under the terms of the Creative Commons Attribution License, which permits unrestricted use, distribution, and reproduction in any medium, provided the original author and source are credited. 


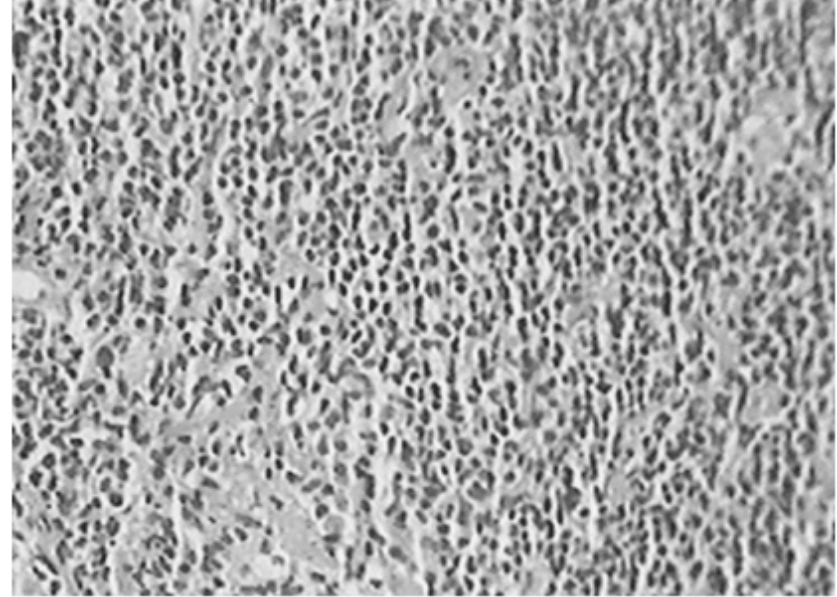

Figure 2: Transbronchial lung biopsy showing diffuse infiltration of atypical lymphoid cells.

in the right upper and middle lobe (Figure 1b). No mediastinal/ hilar lymphadenopathy were seen. Culture of the bronchoalveolar lavage (BAL) showed the growth of Pseudomonas aeruginosa. Thereafter transbronchial lung biopsy was performed. Histopathological examination of the biopsy revealed a diffuse infiltration of atypical lymphoid cells (Figure 2). The cells were monomorphic with rounded nuclei and scant cytoplasm. On immunohistochemistry, the cells were positive for CD 20 and CD 79a. Interspersed in between these cells, few cytokeratin positive cells were seen suggestive of a lymphoepithelial lesion. A diagnosis of MALToma was made based on these findings. The patient had no underlying autoimmune disease. No pathological findings were detected in the bone marrow biopsy. The patient is on chemotherapy and regular follow-up.

\section{Discussion}

Although the lung is a relatively frequent site of secondary involvement of malignant lymphoma with an incidence of 25$40 \%$, primary NHL of the lung is very rare [2]. Not many reports characterizing primary pulmonary NHL are found, however the actual incidence might be higher than those reported, because diseases such as pseudolymphoma, lymphoid interstitial pneumonitis and lymphomatoid granulomatosis are morphologically difficult to distinguish from malignant lymphoma [3]. MALToma is usually indolent with an excellent prognosis. Though it may recur locally, it rarely transforms and few die of the disease.

Primary pulmonary MALToma develops from bronchus associated lymphoid tissue (BALT). BALT is rarely seen in a healthy adult [4], but grows under morbid situation such as bronchiectasis and other chronic inflammatory lung disorders. It is a possibility that repeated episodes of inflammation as a result of infections could have caused MALToma. However it is not clear how much these bacteria contribute to the onset of MALToma.

The symptoms and physical signs of pulmonary MALT lymphoma are highly heterogeneous, and previous studies report $37.5 \%$ to $50 \%$ of patients are asymptomatic on initial diagnosis $[2,5]$. The radiographic presentation of pulmonary MALT lymphomas is not specific, but variable. In Bae et al. study, [6] single or multiple nodules or areas of consolidation were the main patterns of radiographic abnormalities. In other studies, major radiographic abnormalities were described as a lung mass with or without airspace consolidation [2,7].
Pulmonary MALT lymphoma could be diagnosed only by pathologic methods. CT-guided percutaneous lung biopsies and open thoracotomy or VATS lung biopsy are the common methods to obtain samples. Previous studies had reported a low tissue yield from bronchoscopy in primary pulmonary NHL [2]. Only surgical biopsy and resection obtain high yield (64\% of the patients as per Cordier et al. [7] and $90 \%$ of the patients as per Ferraro et al. [2]). In Graham et al. study, [8] the positive predictive rate of the puncture biopsy under CT guide for diagnosing pulmonary NHL was only 25\%. In 2001 , Kurtin et al. [9] reported 41 cases of MALT lymphoma, out of which five were diagnosed by TBLB alone. Zinzani et al. [10] diagnosed $6(50 \%)$ patients with transbronchial lung biopsy/ bronchoalveolar lavage. In 2004, Kim et al. study, [11] bronchoscopy was performed in $83 \%$, but only $30 \%$ showed a diagnostic yield. Huang et al. [12] reported 23 patients of MALT lymphoma, out of which 3 cases were diagnosed by endobronchial biopsies. These results suggest that VATS or open lung biopsy may be the procedure of choice for definitive diagnosis of lymphoma in operable patients. Nonetheless, ancillary immunohistochemical studies, by identifying the monoclonality of lymphoid cells, will probably allow confident diagnosis in some cases when dealing with small biopsies obtained by less invasive procedures such as transthoracic or transbronchial biopsy $[13,14]$

\section{Conclusion}

The primary NHL of the lung is a rare entity, and for the majority of the patients, surgical procedures are still required to establish a definite diagnosis. As MALToma of the lung has an excellent prognosis, it should be considered as a differential and minimally invasive procedures like TBLB might be a suitable option for its diagnosis.

\section{References}

1. Schulte-Pelkum J, Fritzler M, Mahler M (2009) Latest update on the Ro/SS-A Isaacson P, Wright DH (1983) Malignant lymphoma of mucosa-associated lymphoid tissue. A distinctive type of B- cell lymphoma. Cancer 52: 1410-1416.

2. Ferraro P, Trastek VF, Adlakha H, Deschamps C, Allen MS, et al. (2000) Primary non-Hodgkin's lymphoma of the lung. Ann Thorac Surg 69: 993-997.

3. Nicholson AG, Wotherspoon AC, Diss TC, Hansell DM, Du Bois R, et al. (1995) Reactive pulmonary lymphoid disorders. Histopathology 26: 405-412.

4. Tschernig T, Pabst R (2000) Bronchus associated lymphoid tissue (BALT) is not present in the normal adult lung but in different diseases. Pathobiology 68: 1-8.

5. Poletti V, Romagna M, Gasponi A, Baruzzi G, Allen KA (1995) Bronchoalveola lavage in the diagnosis of low-grade, MALT type, B-cell lymphoma in the lung. Monaldi Arch Chest Dis 50: 191-194.

6. Bae YA, Lee KS, Han J, Ko YH, Kim BT, et al. (2008) Marginal zone B-cell lymphoma of bronchus-associated lymphoid tissue: imaging findings in 21 patients. Chest 133: 433-440.

7. Cordier JF, Chailleux E, Lauque D, Reynauld-Gaubert M, Dietemann-Molard A et al. (1993) Primary pulmonary lymphomas. A clinical study of 70 cases in non immunocompromised patients. Chest 103: 201-208.

8. Graham BB, Mathisen DJ, Mark EJ, Takvorian RW (2005) Primary pulmonary lymphoma. Ann Thorac Surg 80: 1248-1253.

9. Kurtin PJ, Myers JL, Adlakha H, Strickler JG, Lohse C, et al. (2001) Pathologic and clinical features of primary pulmonary extranodal marginal zone B-cell lymphoma of MALT type. Am J Surg Pathol 25: 997-1008.

10. Zinzani PL, Tani M, Gabriele A, Poletti V, Stefoni V, et al. (2003) Extranoda marginal zone B-cell lymphoma of MALT-type of the lung: single-center experience with 12 patients. Leuk Lymphoma 44: 821-824.

11. Kim JH, Lee SH, Park J, Kim HY, Lee SI, et al. (2004) Primary pulmonary NonHodgkin's lymphoma. Jpn J Clin Oncol 34: 510-514.

12. Huang H, Lu ZW, Jiang CG, Li J, Xu K, et al. (2011) Clinical and prognostic characteristics of pulmonary mucosa- associated lymphoid tissue lymphoma: a retrospective analysis of 23 cases in a Chinese population. Chin Med J (Engl) 124: $1026-1030$ 
Citation: Gupta S, Goel K, Kaur J (2012) MALT Lymphoma Diagnosed on Transbronchial Lung Biopsy: A Case Report. J Pulmonar Respirat Med 2:117. doi:10.4172/2161-105X.1000117

Page 3 of 3

13. Betsuyaku T, Munakata M, Yamaguchi E, Ohe S, Hizawa N, et al. (1994) Establishing diagnosis of pulmonary malignant lymphoma by gene rearrangement analysis of lymphocytes in bronchoalveolar lavage fluid. Am J Respir Crit Care Med 149: 526-529.
14. Zaer FS, Braylan RC, Zander DS, Iturraspe JA, Almasri NM (1998) Multiparapetric flow cytometry in the diagnosis and characterization of lowgrade pulmonary mucosa- associated lymphoid tissue lymphomas. Mod Pathol 11: $525-532$. 